\title{
DESEOS DE FUTURO, INTENCIONALIDADES Y CONSTRUCCIÓN DE TERRITORIOS. La experiencia de zonas rurales en la región chaqueña argentina
}

\author{
Marcelo Enrique Sili* \\ Universidad Nacional del Sur
}

\begin{abstract}
RESUMEN
Este trabajo analiza las formas y mecanismos con que los múltiples actores involucrados en un territorio generan acciones en vistas a construir el futuro. Para poder eludir el uso del concepto de desarrollo como marco referencial, este trabajo moviliza el concepto de acción territorial, pues el mismo permite analizar más cabalmente las formas con que múltiples actores, con diversas y a veces contradictorias representaciones acerca del futuro, ponen en marcha iniciativas para construir y gestionar sus territorios. Esta propuesta conceptual y metodológica de carácter cualitativa se pone en práctica en un territorio rural del Departamento de Pirané en el centro de la región chaqueña, territorio que ha vivido procesos de cambio territorial (deforestación, conflictos por el uso y la tenencia de la tierra, entre otros), y que por lo tanto puede ser considerado un buen caso de análisis, no sólo de transformaciones territoriales, sino también de mecanismos y formas de construir la acción pública, privada y colectiva en torno a un proyecto de futuro territorial. La investigación permite observar como si bien se visualiza un deseo de futuro por parte de los múltiples actores locales, no existen las condiciones organizacionales ni los instrumentos para construir dicho proyecto de futuro.

Palabras claves: acción territorial; desarrollo territorial; representaciones sociales; actores; Argentina

\section{FUTURE WISHES, INTENTIONALITIES AND CONSTRUCTION OF TERRITORIES. THE EXPERIENCE OF RURAL AREAS IN THE CHACO REGION OF ARGENTINA}

\section{ABSTRACT}

This work analyzes ways and mechanisms by which the diverse actors involved in a territory act with the aim to build the future. The concept of territorial action is encouraged in this work, in order to avoid the one of development. The former allows a thorough analysis of the different ways the actors, with different and sometimes contradictory ideas about the future, set new initiatives in motion to build and manage their territories. This qualitative-type of conceptual and methodological proposal is put into practice in a rural territory of the Department of Pirané (Province of Formosa) in the center of the Chaco region. Since this territory has lived paradigmatic processes of territorial change (such as deforestation, conflicts for the use and possession of lands, among others), it can be considered as a good case of analysis, not only of territorial transformations, but also of mechanisms and ways of building the public, private and collective action around a project of territorial future. This investigation allows to observe how, although a desire of future is sought by the multiple local actors, neither the organizational conditions nor the instruments to build this project for the future exist.

Keywords: territorial action; territorial development; social representations; actors; Argentina

* CONICET - Departamento de Geografía y Turismo. Universidad Nacional del Sur. 12 de Octubre y San Juan, (8000), Bahía Blanca, Argentina. Sili.marcelo@gmail.com

Fecha de recepción: 29 de mayo de 2019. Fecha de aceptación: 30 de agosto de 2019

Papeles de Geografía, 65 (2019), 30-48 


\section{INTRODUCCIÓN}

Los procesos y las políticas de desarrollo local y regional son temas arduamente analizados y trabajados en el contexto de América Latina en el último medio siglo. Hay tres grandes razones que sostienen esta fuerte preocupación, en primer lugar porque existe una clara necesidad de mejorar la calidad de vida en numerosas zonas de esta vasta geografía de América Latina, zonas donde persisten todavía elevados niveles de pobreza y marginalidad. En segundo lugar porque es necesario reducir las brechas de ingresos y calidad de vida entre regiones en los países, América Latina se ha caracterizado históricamente por mantener niveles de desigualdad territorial muy elevados, con regiones muy pobres y marginales y otras regiones más dinámicas con mayores niveles de ingreso y calidad de vida, estas profundas desigualdades contribuyen también a mantener y consolidar los grandes problemas estructurales de la región (deseconomías de escala, mantenimiento de altos niveles de violencia e inseguridad, deterioro de recursos naturales, etc.). En tercer lugar, las políticas de desarrollo local y regional aparecen como la fórmula para alcanzar estándares y niveles de modernización comparables a los países de Europa Occidental o de América del Norte.

Esta preocupación por el desarrollo se traduce en la promoción de emprendimientos productivos, la construcción de infraestructuras y equipamientos, la animación cultural, u otro tipo de iniciativas tanto formales y estructuradas dentro de un plan, como informales sin conexión con otras actividades. Todas estas iniciativas surgen desde los gobiernos locales, provinciales y nacionales, o también desde sectores sociales y productivos, a través de organizaciones sociales o empresariales. Más allá de quien pone en marcha estas acciones y de la naturaleza de las mismas, la evidencia en la región, muestra que hay dos elementos claves en torno a estas iniciativas. En primer lugar las iniciativas se generan y ponen en marcha con un bajo nivel de coordinación, con superposición, conflictos y competencia entre ellas, lo cual lleva a la pérdida de eficacia y de impacto (RIFFO, 2013; SILI, 2018), así muchas veces en un mismo territorio, múltiples actores ponen en marcha iniciativas que entran en conflicto unas con otras, o se superponen esfuerzos y se dilapidan recursos debido a la duplicidad de las mismas. Un segundo elemento es que los actores involucrados tienen una clara divergencia sobre el significado y las representaciones en torno al desarrollo y por ende sobre los objetivos que persiguen las acciones puestas en marcha (IPARRAGUIRRE, 2017), esto torna más confuso los objetivos y el modelo de futuro a seguir.

Esta falta de coordinación y esta divergencia o falta de consenso en torno a los objetivos de "desarrollo", pueden ser observados en múltiples escalas, desde los niveles nacionales, hasta los locales, lo cual define todo un nuevo escenario territorial que requiere de políticas y estrategias de desarrollo más adecuadas a este nuevo contexto de fragmentación. Dentro de este nuevo escenario histórico, los tradicionales enfoques y modelos de intervención, pensados para territorios ya estructurados, con políticas jerárquicas, con roles y funciones claramente definidos, y con un modelo de modernización y crecimiento claramente definido y socialmente aceptado, ya no generan los resultados esperados (SILI, 2016).

Teniendo en cuenta este nuevo escenario signado por la globalización, la complejidad de procesos y la fragmentación de la acción pública, privada y colectiva, este artículo tiene como objetivo mostrar como los diferentes actores involucrados en un lugar determinado construyen sus acciones en vistas a un ideario de desarrollo. Interesa entender las acciones puestas en marcha en un territorio, la organización de los actores involucrados, las representaciones que estos tienen en torno al futuro del mismo, las vinculaciones de estas iniciativas y actores con otros niveles escalares (con las propuestas de orden regional y nacional) y con otras iniciativas, y por qué a pesar de todos los esfuerzos que se realizan, los impactos de estas iniciativas suelen ser muy pobres.

La hipótesis que sustenta nuestro trabajo es que en muchos territorios, a pesar que se ponen en marcha en forma permanente, múltiples iniciativas por parte de diferentes actores, estas no generan los resultados planteados o esperados. Esto se debería a tres factores:

Papeles de Geografía, 65 (2019), 30-48 
1. en primer lugar porque no se puede definir una visión y proyecto compartido de futuro,

2. en segundo lugar porque se genera una profunda fragmentación y desarticulación entre los actores involucrados en el territorio, producto de fuertes diferencias en las representaciones del desarrollo, en las lógicas de actuación y en las rítmicas sociales de los actores (IPARRAGUIRRE, 2017) y

3. por último porque no hay actores capaces de acompañar en la construcción y gestión de un proyecto territorial (LANDEL et al., 2011).

Para poder dar cuenta de estos procesos y esta hipótesis de trabajo, se analiza la situación del sur del Departamento Pirané, en la Provincia de Formosa, en el centro de la región del Chaco argentino, un territorio que puede ser considerado como un modelo representativo de acción territorial, con un doble objetivo. En primer lugar generar nuevos conocimientos sobre las formas como las sociedades construyen, sobre la base de una fuerte diversidad de representaciones del desarrollo, sus iniciativas generadoras de un orden territorial. Y en segundo lugar definir un modelo analítico de las formas y procesos de construcción territorial, susceptible de ser replicado en otros ámbitos.

\section{MARCO CONCEPTUAL}

Diferentes perspectivas conceptuales pueden ser planteadas para este tipo de análisis, la más tradicional se vincula con el public management en su versión anglosajona (GRUENING, 2001) y en la action publique territoriale en su versión francesa (DOUILLET et al., 2015; LANDEL et al., 2011). Estas perspectivas conceptuales pueden sustentar el análisis del rol del Estado y de las políticas públicas nacionales, provinciales y locales en la construcción y la organización del territorio. Un indicador de ello es que gran parte de la producción científica de las últimas décadas ha estado sustentada en esta perspectiva. Sin embargo, la profunda transformación operada en el contexto latinoamericano y argentino, la globalización y la descentralización de por medio (CEPAL, 2016), han definido un nuevo contexto en el cual los actores claves del cambio territorial no son sólo el Estado, sino, y cada vez más, los actores privados (empresas especialmente) y colectivos (organizaciones sociales, cooperativas, etc.). Teniendo en cuenta esta nueva realidad, es necesario una base conceptual más amplia que permita comprender el rol y el accionar de múltiples actores, es por ello que se apela al concepto de acción territorial como soporte conceptual y metodológico para el análisis (SILI, 2018).

Para poder dar cuenta de estas hipótesis de investigación es necesario partir en primer lugar del marco de referencia conceptual de la acción territorial, el cual se sustenta en una definición amplia de territorio, entendido éste como un espacio geográfico que carga con un conjunto de intencionalidades políticas, sociales, productivas, culturales (proyectos) que se plasman o concretan en función de las capacidades de los actores o los grupos de estos para llevarlas a cabo (capacidad de acción). Así, el territorio no es entonces un simple soporte físico, sino la "arena" donde los grupos sociales construyen un devenir, por lo tanto las características de estos territorios no van a depender sólo de sus condiciones naturales, ni de su configuración espacial, sino también de las formas en cómo se articulan entre sí los proyectos de cada uno de los actores y cómo a partir de esta articulación son capaces de valorizar y gestionar el lugar y construir un proyecto de futuro.

En función de esta concepción, la acción territorial puede ser pensada como el proceso dinámico a partir del cual los actores públicos, colectivos y privados construyen acciones de diferente índole, institucionalizados a veces en planes o proyectos de desarrollo o no, en vistas a organizar y gestionar sus territorios, en función de un ideario o modelo deseado de futuro, el cual no siempre esta explicitado, ni es hegemónico o compartido por el conjunto de los actores (BUSTOS CARA, 2008; SILI, 2018). Estas acciones están estructuradas bajo un modelo de gobernanza, condicionadas por las normas o reglas formales e informales vigentes y el intercambio de recursos, que se caracterizan por ser escasos y estar inequitativamente distribuidos (MANZANAL et al., 2012).

Papeles de Geografía, 65 (2019), 30-48 
Esta acción constructora de territorios integra el pasado dada la memoria y las estructuras físicas heredadas, el presente por las condiciones de contexto actuales y el futuro de acuerdo a las imágenes y representaciones que tenemos sobre ese futuro y que determinan las intencionalidades en la toma de decisiones. Esta construcción es relacional en el sentido que siempre integra y coordina necesariamente múltiples y diversas iniciativas de actores con lógicas de acción y ritmos de vida muy diferentes, pues todos los actores y los grupos sociales involucrados no necesariamente siguen las mismas lógicas y las mismas rítmicas culturales (IPARRAGUIRRE, 2017), de allí que la acción territorial es también un claro generador de conflictos entre actores y grupos sociales, pues las acciones de unos muchas veces chocan o limitan las acciones de otros. Así, tal como lo plantea Bauman "Los hombres hacen su propia historia, pero no la hacen a su libre arbitrio, bajo circunstancias elegidas por ellos mismos, sino bajo aquellas circunstancias con que se encuentran directamente" (BAUMAN, 2017, p. 150). Si bien la acción territorial se construye a partir de una intencionalidad de los actores, y dado que estas intencionalidades son muy diferentes y no siguen un modelo de futuro deseado por todos por igual, los resultados del conjunto de las acciones en un territorio no siempre terminan configurando situaciones de mayor desarrollo. Al contrario, en muchas ocasiones se generan situaciones de mayor desequilibrio, deterioro o empobrecimiento, dado que pueden prevalecer acciones de carácter depredatorias, de explotación irracional de los recursos o de usos indebidos, por encima de acciones movilizadas por deseos de usos sostenibles o de gestión más racional de los recursos (POUTHIER, 2013). Así, el análisis de la acción territorial es un poderoso instrumento para entender como se construyen los territorios y su devenir, pensando el futuro de una manera más descarnada y real, sin caer en la trampa y la ilusión del trayectorismo occidental (APPADURAI, 2015) por la cual los territorios están inevitablemente sujetos y condicionados a seguir una línea de tiempo que nos conduce a escenarios de superación y progreso, y que siempre implicó que toda política e intervención debe servir necesariamente para remover los obstáculos que frenan o impiden avanzar hacia ese escenario predestinado de progreso. Al contrario, a través del análisis de la acción territorial podemos entender que los territorios también pueden evolucionar hacia escenarios muy diferentes, con deterioro ambiental y de la calidad de vida.

Los actores involucrados en la acción territorial pueden ser diferenciados en públicos, privados o colectivos. La acción pública es ejercida por aquellos sujetos que basan su propósito de intervención en el hecho de que representan a los ciudadanos, y se rigen por la estructura política administrativa del Estado. La lógica de acción implica actuar en función de aquellas alternativas que mejoren la capacidad para obtener consenso político, promoviendo los acuerdos y compromisos que sean necesarios. Los actores públicos están integrados por el gobierno, que representa el poder ejecutivo en los diferentes niveles de competencia; la burocracia y la administración pública, que ejecuta las decisiones gubernamentales; el parlamento y los órganos de justicia (DENTE et al., 2014). Los actores privados, en tanto, reúnen a los individuos, empresas y corporaciones que intervienen a partir de un interés específico que implica en muchas ocasiones la maximización de beneficios económicos o el logro de beneficios sociales o culturales. La dinámica que se haga preponderante en el territorio incidirá directamente sobre sus intereses, sea por los costes que implica afrontarla o por la posibilidad de incrementar alguna de sus posiciones en el espacio social (BOURDIEU, 2005). Finalmente, la acción colectiva, implica la integración de distintos actores en forma de asociación para asumir la representación de intereses que no pueden actuar por ellos mismos, tales como la salud, la educación, la igualdad, la protección del medio ambiente, la seguridad, la lucha contra la pobreza, etc. Estos intereses generales suelen estar lejos de encontrarse entre los prioritarios de los actores políticos y privados, por lo que pujan por sus propios mecanismos de participación (CROZIER et al., 1977). El propósito de intervención busca contribuir al bien común, incorporando ciertas estructuras organizativas que asumen la tutela de intereses generales y los representan en las distintas instancias que se requiera para evitar que sean desatendidos (BUSTOS CARA, 2008; DENTE et al., 2014).

Las acciones territoriales pueden tener diferentes niveles de complejidad, hay acciones que pueden ser consideradas como iniciativas cotidianas de los actores en términos individuales (MOINE et al.,

Papeles de Geografía, 65 (2019), 30-48 
2013) y con baja capacidad para estructurar cambios en el corto plazo. Estas acciones cotidianas que "no surgen necesariamente de un plan consciente, sino simplemente de lo que la gente hace, siente, percibe y llegan a articular en su búsqueda de significado para su vida cotidiana" (HARVEY, 2013, p. 15). En el mismo sentido Gumuchian y otros plantean que "el territorio debe ser pensado a través de un conjunto de microeventos, entendiendo por microeventos las actitudes y los comportamientos de los actores en el territorio" (GUMUCHIAN et al., 2003, p. 48). Muchos de estos microeventos o acciones individuales o colectivas producen resultados cuya dimensión territorial es menor, sin embargo la red de estas acciones se transforman en un momento dado o confluyen en la construcción de un proyecto territorial. Pero también hay acciones de mayor complejidad y envergadura, con gran capacidad para estructurar cambios territoriales, llevadas a cabo por uno o múltiples actores y con más fuerza y capacidad para organizar y estructurar el territorio. Históricamente estas acciones fueron planificadas, pautadas y organizadas por los gobiernos.

Las acciones pueden ser diferenciadas según el tipo o naturaleza de las mismas. Puede ser de desarrollo económico, producción y empleo, de carácter sociocultural, acciones político institucionales, de gestión ambiental, de creación de infraestructuras o de ordenamiento territorial.

Finalmente, un último aspecto que es necesario observar en las acciones territoriales, son los recursos que movilizan cada grupo de actores involucrado en las mismas. Subirats (2008, p. 94) definen recurso como "un activo de materias primas de las que los actores públicos y privados se sirven para llevar a cabo sus acciones". Es importante tener en cuenta que no existen recursos de los territorios "en sí", sino que estos surgen de la intencionalidad, la movilización y la cooperación de los actores que con cierto grado de autonomía los construyen a partir de su relación con el sistema de producción (KEBIR, 2006; LANDEL et al., 2011). Así, los actores estructurados por diferentes elementos de la economía, la cultura y la naturaleza, interactúan con los bienes que le vienen dados (fauna, flora, patrimonio, conocimiento, historia, etc.), imbuyéndolos de un mayor o menor valor en función de sus objetivos e intereses en el entramado territorial, seleccionando aquellos objetos que considera más relevantes para sus estrategias y excluyendo a otros. Es cada sociedad y sus individuos, la que activa sus componentes y los resignifica en el tiempo en función a nuevos contextos, nuevos usos y nuevas demandas. La dotación de estos activos entre los diferentes actores, así como su producción, gestión, explotación e intercambio va a influir directamente en la acción territorial.

\section{EL TERRITORIO DE ANÁLISIS}

Este proceso de construcción territorial se analiza en una sub-región particular de la vasta región chaqueña de América del Sur y más específicamente de la Argentina, un ámbito territorial constituido por las Provincias de Formosa, Chaco, Santiago del Estero, y el este de las Provincias de Salta, Tucumán, Catamarca, La Rioja, y el norte de las Provincias de San Luis, Córdoba y Santa Fe. Dicha región muestra los mayores niveles de pobreza y desigualdad en el contexto argentino, con críticas situaciones ambientales debido a la deforestación de su masa boscosa para realizar ganadería y cultivos de soja y otros cereales y oleaginosas, y con muy limitadas capacidades de desarrollo socioeconómico debido a una estructura económica primaria dependiente de actividades agropecuarias y de empleos públicos. Dentro de este contexto se localiza el territorio de Pirané Sur en el sudeste de Formosa, a 150 kilómetros de la capital provincial y 150 de la ciudad de Resistencia. El relieve es una planicie cubierta por praderas naturales, montes en forma de isletas y montes en galería sobre los albardones de riachos, y grandes esteros, lagunas y cañadas con palmares. La temperatura media es de $22{ }^{\circ} \mathrm{C}$, con variaciones extremas que llegan a superar en verano los $45^{\circ} \mathrm{C}$. La precipitación media anual es de $1140 \mathrm{~mm}$, con lluvias más abundantes en la primavera, el verano y el otoño. 
FIGURA 1

Localización del área de estudio

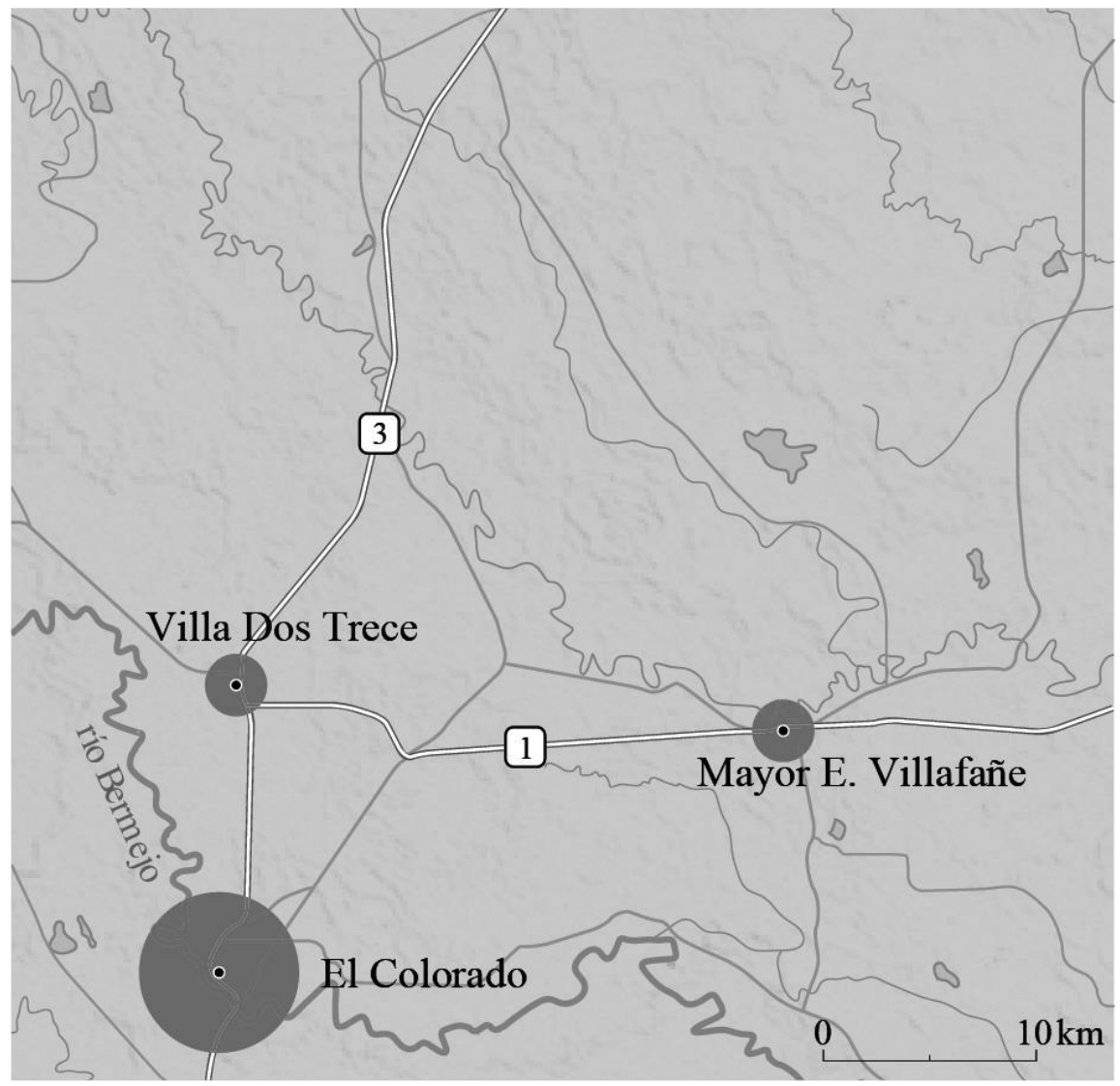

\section{Referencias}

población 2010

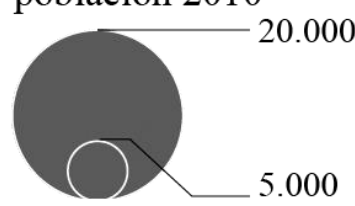

3 ruta provincial

- rutas y caminos secundarios

0 a $200 \mathrm{~m}$

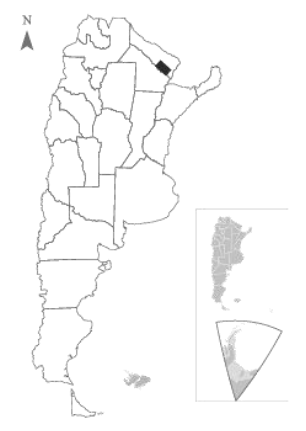

Fuente: elaboración personal

El principal centro urbano es la localidad de El Colorado, situado en las márgenes del río Bermejo. Tiene unos 18.000 habitantes y está en constante crecimiento por la llegada de migrantes procedentes del campo. Los otros dos centros urbanos son Villa Dos Trece, con 7.000 habitantes, y Mayor Edmundo Villafañe con 5.000. Más allá de estas localidades, hay 47 colonias agrícolas (agrupamiento de población que vive en parcelas agrícolas muy cercanas unas con otras), donde residen pueblos originarios, criollos y descendientes de inmigrantes europeos (ucranianos, yugoslavos, alemanes, croatas). Estos últimos se instalaron a partir de 1930, en respuesta a una política de colonización y al auge del cultivo del algodón. También hay familias de origen paraguayo, correntino y chaqueño. Históricamente estas colonias tuvieron una activa vida social, que en la actualidad se ha trasladado a los pueblos donde se concentra más del $70 \%$ de la población de la zona. El análisis de la acción territorial se realiza en todo este territorio pero se centra principalmente en la localidad de El Colorado.

Solo la localidad de El Colorado cuenta con una mayor dotación de infraestructuras y equipamientos. El resto de las localidades y el campo carece de las infraestructuras, equipamientos y servicios necesarios para garantizar una adecuada calidad de vida, siendo la insuficiente provisión de agua potable uno de los principales problemas, no sólo porque no se cuenta con las infraestructuras necesarias (acueductos, pozos de profundidad, plantas potabilizadoras), sino porque debido a un largo período de sequía, las napas freáticas han descendido a niveles muy bajos imposibilitando su 
captación o porque el agua proveniente de las mismas tienen altos niveles de salinización que impiden su consumo por la población y por los animales. Esta situación, y la baja rentabilidad de los principales cultivos (algodón y hortalizas), han generado un continuo éxodo de población de los campos y pequeños pueblos hacia la localidad de El Colorado y a las ciudades de Formosa y Resistencia, con las cuales hay buena conectividad a través de rutas pavimentadas.

En las últimas décadas, y producto del cambio en las condiciones macroeconómicas de los años 90, la producción agropecuaria vivió un significativo proceso de transformación en esta zona. En primer lugar disminuyó la rentabilidad y los ingresos de los pequeños productores, muchos de los cuales abandonaron sus campos. En segundo lugar se produjo un notable cambio tecnológico - no al alcance de todos los productores- que permitió la generación de nuevas actividades y cultivos con altos niveles de productividad. Y en tercer lugar emergieron nuevos actores no locales vinculados, en general, a la región pampeana, que compraron o arrendaron campos (muchos de ellos vendidos por los pequeños productores) para desarrollar nuevas actividades ganaderas o para producir soja u otros cultivos (girasol, maíz, sorgo, etc.) en tierras que anteriormente estuvieron dedicadas a los cultivos de autoconsumo o al algodón, o en tierras boscosas que se han deforestado. De esta manera, este territorio, que históricamente se caracterizo por su relativa homogeneidad y la producción de algodón, dentro de un paisaje de monte chaqueño, se caracteriza hoy por ser un territorio de avance de nuevas actividades y cambios de usos del suelo a partir de la incorporación de nuevas lógicas de producción llevadas a cabo por empresas de mayor tamaño, siendo actualmente Pirané el primer Distrito sojero y el segundo ganadero de la Provincia de Formosa.

Dentro de este contexto de profunda transformación, los pequeños productores mantienen explotaciones que en promedio tienen entre 10 y 50 has., y en su conjunto representan el $64 \%$ de las explotaciones de la zona siendo, a pesar de la emergencia de nuevas lógicas de producción, las que estructuran la vida social. Realizan cultivos intensivos para autoconsumo y también cultivos de renta como hortalizas pesadas (cucurbitáceas) en contraestación para lograr llegar rápidamente al mercado, y algodón. Además desarrollan actividades de granja en las que incluyen cría de aves para producción de huevos y carne. Algunas familias crían ganado menor como cerdos y/o chivos para autoconsumo y venta de excedentes o explotan el monte nativo para la venta de madera para la elaboración de muebles y carbón. También poseen algunas vacas para ordeñe y producción de queso criollo, mientras que los terneros les sirven como alternativa ante imprevistos que deban afrontar.

Las grandes explotaciones, por su parte se dedican principalmente a la ganadería de cría extensiva, y actualmente algunas de ellas han incorporado la producción de cereales y oleaginosas. Estos van cambiando su tipo de producción en función de la acumulación de humedad existente en el suelo y siguiendo los precios del mercado, razón por la cual varían su producción entre soja, girasol o maíz, orientando la producción para la venta en el mercado o para el consumo ganadero dentro de sus campos o en la zona. En cambio, los pequeños y medianos productores se vuelcan hacia la siembra de algodón por su resistencia a la falta de agua y a las altas temperaturas, además de su fácil comercialización, ya que una de las principales limitaciones que éstos tienen para cultivar soja es el costo que tiene su comercialización (flete y carta de porte).

La emergencia de nuevos actores en el sector agropecuario y las nuevas actividades está transformando la matriz productiva regional. Si bien la producción agropecuaria crece notablemente y se dinamizan los sectores de la construcción, los hoteles, comedores y algunos talleres y servicios vinculados a la maquinaria agrícola, el éxodo de los campos continúa. Son los pequeños productores, pero muy especialmente sus hijos los que migran hacia los pueblos u otras ciudades debido a la falta de oportunidades de empleo, pues bajo este nuevo modelo de organización productiva de mayor capitalización y mayor escala solo se necesita un mínimo de personal para tareas de baja complejidad, en tanto que la mano de obra calificada (operarios de maquinaria agrícola de complejidad) muchas veces proviene de las mismas provincias de origen de los nuevos empresarios. Este proceso de éxodo de la zona es ejemplificador de lo que sucede en el campo argentino. En 1970, Pirané sur contaba con más de 20.000 habitantes en el campo, mientras que en el año 2010 se contabilizan menos de 8.000 
habitantes. En idéntico lapso, los pueblos más grandes pasaron de 5.000 habitantes a más de 25.000 habitantes.

El resto de las actividades productivas se limita a la provisión de bienes y servicios de baja complejidad para la población local. Los de mayor complejidad deben canalizarse a través de las ciudades de Formosa y Resistencia, o las ciudades de la región pampeana (Córdoba y Rosario). La industria por otro lado es mínima en esta región.

Frente a estas transformaciones del modelo productivo regional, en ésta como en otras regiones con problemáticas similares, hay una gran cantidad de instituciones y organismos que intentan desarrollar acciones para mitigar los efectos negativos del avance de la frontera agropecuaria y del cambio de modelo productivo. En primer lugar, se intenta regular el proceso de deforestación y avance de la frontera agropecuaria a través del Plan de ordenamiento territorial provincial que limita y regula las áreas a deforestar (no obstante dicho instrumento es muy laxo comparado con otras provincias argentinas, dado que el mismo ha permitido asignar una importante proporción de áreas para deforestar). En segundo lugar a través de la creación de infraestructuras (rutas, electrificación rural, conectividad, escuelas, viviendas rurales) y el apoyo a la producción y a la comercialización en el sector de pequeños y medianos productores van en este sentido. Todas estas iniciativas son llevadas a cabo por los municipios, el gobierno provincial a través de sus diferentes ministerios, pero especialmente a través del Ministerio de la Producción y Ambiente y del Gobierno nacional a través del INTA y diversos programas de desarrollo rural del Ministerio de Agricultura.

Estas características generales permiten tipificar a este Distrito como una zona típica de la región chaqueña, con una baja calidad de vida en general, aunque con esfuerzos de mejorar la misma en las localidades, las cuales se han transformado en el centro receptor de la población rural, con una estructura económico productiva dependiente de un sector agropecuario cada vez más dual, con sectores que se dinamizan al ritmo de la llegada de inversores externos y con otros sectores históricamente empobrecidos de la agricultura familiar.

\section{METODOLOGÍA DE ANÁLISIS}

Desde el punto de vista metodológico, este trabajo es producto de una investigación de carácter cualitativo, la metodología de investigación se llevo a cabo en tres grandes etapas que permitieron consolidar paso a paso la información y el análisis inicial a través de miradas complementarias de diferentes actores. Las etapas de trabajo fueron las siguientes:

Primera etapa de recopilación de información de base:

En primer lugar se realizaron entrevistas en profundidad a 12 referentes claves de la acción pública, la acción privada y la acción colectiva, gran parte de ellos con responsabilidades en ámbitos políticos, institucionales o empresariales. Todas estas entrevistas tuvieron el mismo guión y fueron realizadas en forma individual, las mismas tuvieron como objetivo identificar las representaciones que los actores tienen sobre el desarrollo del distrito, sobre las acciones más significativas puestas en marcha a nivel local y sobre las formas como estas acciones se llevan adelante. En el anexo se presentan las principales preguntas realizadas a los entrevistados.

Las variables claves sobre las que se trabajo en las entrevistas han sido las siguientes:

- Caracterización general del entrevistado (sexo, edad, actividad, sector al cual pertenece)

- Opinión sobre las principales fortalezas del Distrito

- Opinión sobre los principales problemas del distrito

- Visión del escenario de futuro del Distrito

- Acciones que los actores identifican que están en marcha en el Distrito

- Recursos movilizados para la realización de estas acciones

- Actores responsables de las acciones

- Mecanismos y formas de ejecución de las acciones

- Resultados de las acciones

- Limitantes a la puesta en marcha de las acciones

Papeles de Geografía, 65 (2019), 30-48 
Toda la información recogida en las entrevistas se sistematizo y codificó en una hoja de cálculo lo cual permitió elaborar una tabla de frecuencias de todas las respuestas de todos los entrevistados, considerando como elemento de clasificación primario el tipo de categoría de entrevistado (acción pública, acción colectiva y acción privada). Con esta información dividida por tipo de actor se realizaron los cruces con las diferentes variables, lo cual permitió analizar y caracterizar cada situación en particular, realizar análisis descriptivos e identificar y analizar los discursos de cada uno de los actores. La tabla 1 presenta un detalle de los entrevistados y sus lugares de referencia

TABLA 1

Actores entrevistados

\begin{tabular}{|l|l|l|}
\hline & \multicolumn{1}{|c|}{ Cargo } & \multicolumn{1}{c|}{ Lugar } \\
\hline \multirow{4}{*}{ Acción pública } & Técnico INTA & Villafañe \\
\cline { 2 - 3 } & Técnico INTA & El Colorado \\
\cline { 2 - 3 } & Técnico Ministerio de la Producción y Ambiente & Villafañe \\
\cline { 2 - 3 } & Funcionario municipal & El Colorado \\
\cline { 2 - 3 } Acción privada & Funcionario municipal & Villafañe \\
\cline { 2 - 3 } & Empresario metalúrgico & El Colorado \\
\cline { 2 - 3 } & Productor agropecuario mediano & Villafañe \\
\cline { 2 - 3 } & Empresario servicios agropecuarios & El Colorado \\
\cline { 2 - 3 } Acción colectiva & Profesional servicios veterinarios & Villa 213 \\
\cline { 2 - 3 } & Personal Cooperativa servicios & El Colorado \\
\cline { 2 - 3 } & Federación Agraria & El Colorado \\
\cline { 2 - 3 } & Asociación de feriantes & Villa 213 \\
\hline
\end{tabular}

Fuente: Elaboración propia en base a trabajo de campo.

Segunda etapa de validación de información:

En un segundo momento, y para poder tener más fortaleza en la validación de la información recopilada y analizada, se realizaron 12 entrevistas más a ciudadanos sin participación o responsabilidades directas en el sector público, ni en organizaciones sociales ni en el sector privado, la mayoría de ellos maestros y empleados en diferentes actividades, en comercios o industrias locales. El objetivo de estas entrevistas complementarias fue cotejar y validar los resultados de la primera serie de entrevistas.

Tercera etapa de validación definitiva y enriquecimiento de conclusiones:

En un tercer momento, y con el objetivo de continuar fortaleciendo la administración de la prueba, se realizó un breve informe el cual se distribuyó a 4 referentes de la comunidad que no participaron en la ronda de entrevistas previas, con la presencia de todos ellos se realizó un focus group para debatir los resultados de esta investigación. Este trabajo grupal permitió validar la hipótesis de trabajo y enriquecer el análisis y las conclusiones a las cuales se arribaron.

\section{Resultados}

Para el análisis de la acción territorial interesa entender desde el primer momento no solo las condiciones estructurales del lugar, sino también la mirada que los actores locales tienen sobre el mismo y sobre su futuro, pues es a partir de dichas miradas que se movilizan y construyen las acciones territoriales. 
FIGURA 2

Principales debilidades del El Colorado según la opinión de los actores locales

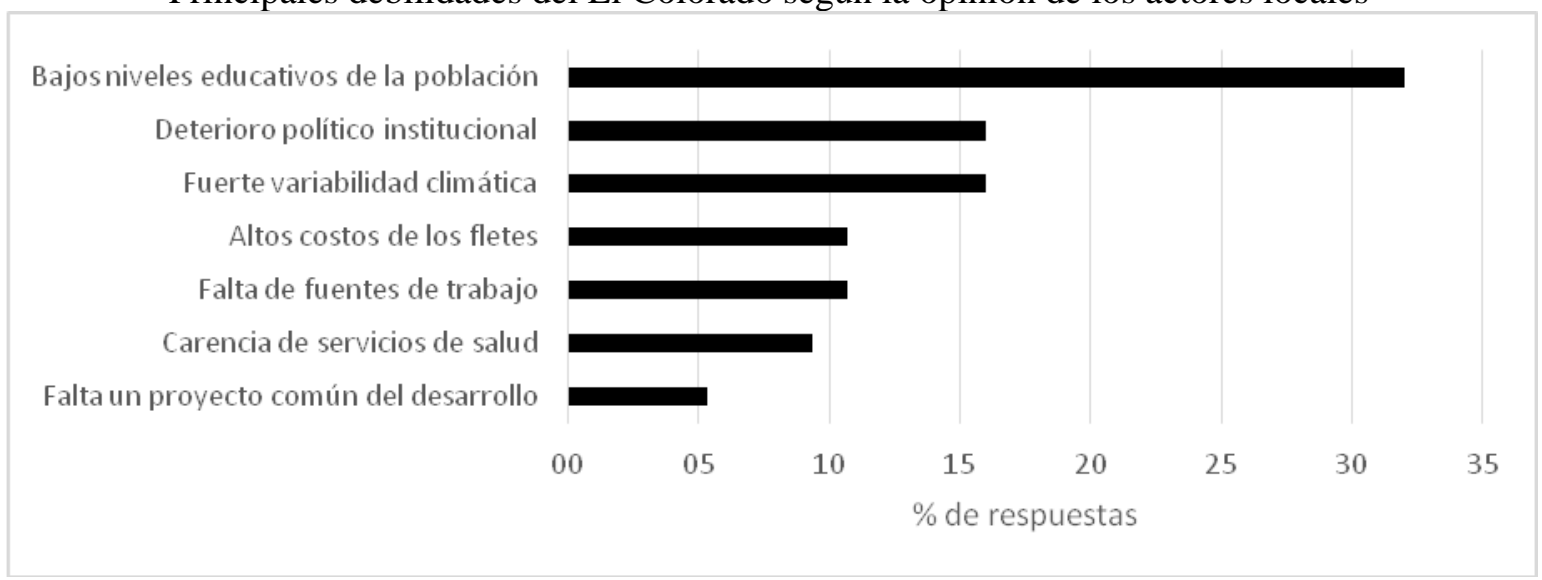

Fuente: Elaboración personal en base a entrevistas locales

Tal como lo presenta la figura 2, a la vista de los actores locales las principales debilidades de este territorio son, en primer lugar los bajos niveles educativos de la población y en segundo lugar el deterioro político institucional, con gobiernos locales que no se renuevan desde hace décadas, con una escasa participación y vida democrática. En tercer lugar aparece la falta de una visión También en segundo lugar aparece la problemática del cambio climático, expresado a nivel local con la creciente variabilidad de eventos catastróficos (lluvias extremas, inundaciones frecuentes, tornados, sequías, etc.), lo cual afecta la vida en los pueblos pero por encima de todo la producción agropecuaria, base de la economía local. Un segundo grupo de problemáticas lo constituye los altos costos de los fletes debido a las grandes distancias a los mercados, lo cual repercute en la perdida de competitividad de sus sistemas productivos. Otro elemento crítico planteado por numerosos actores es la falta de fuentes de trabajo que permiten arraigar a la población, especialmente a los más jóvenes que parten de la localidad en busca de trabajo en la capital de la Provincia o en provincias vecinas. La falta de servicios de salud también aparece como un elemento critico a la vida de la comunidad local. Finalmente, un elemento que emerge en el discurso de la población es la falta de un proyecto común de desarrollo, es decir una guía o proyecto local hacia el cual se pretenda avanzar.

Es importante observar cuáles son los actores que plantean estas problemáticas locales. Para la acción colectiva los principales problemas son el bajo nivel educativo de la población, el deterioro político institucional y la falta de fuentes de trabajo. Para la acción privada es principalmente el bajo nivel educativo de la población y los factores que afectan al desarrollo económico productivo como son los altos costos de los fletes y la fuerte variabilidad climática. En cambio, para los actores vinculados a la acción pública los principales problemas son la fuerte variabilidad climática y la falta de fuentes de trabajo, de la cual responsabilizan a las políticas macroeconómicas y al sector privado. Para estos, los bajos niveles educativos de la población, la falta de un proyecto común de desarrollo y el deterioro político institucional no constituyen problemas locales.

Esta percepción de los problemas señala una clara diferencia entre actores, lo cual depende del rol y las responsabilidades que juegan en la vida local.

Las diversas entrevistas realizadas en las diferentes rondas de trabajo no permitieron rescatar problemáticas que aparecen como claves en la región chaqueña como son los problemas ambientales derivados de la deforestación y el conflicto por la tenencia de la tierra. La ausencia de comentarios sobre estas problemáticas se debe a que esta zona (históricamente ganadera y en menor medida 
agrícola), no sufrió el mismo proceso de deforestación en las últimas décadas como el resto del Departamento de Pirané, en donde la deforestación fue sumamente importante, ni tampoco tuvo conflictos de magnitud por la tenencia por la tierra como otras zonas de la región del Chaco. Las problemáticas de deforestación y de reorganización de la estructura agraria fueron importantes en esta zona de Pirané a inicios y mediados de siglo XX, en plena etapa de colonización.

Por otro lado, las principales fortalezas planteadas por los actores locales son en primer lugar la disponibilidad de recursos naturales susceptibles de aprovechar para el desarrollo productivo local, con especial referencia a la calidad de los suelos, los bosques, el río. Aparece también la fuerte diversidad cultural propia de la zona debido a que se trata de un área colonizada por migrantes de muy diversos orígenes, italianos, españoles, rusos, polacos, croatas, sirios, además, claro está, de la presencia de criollos y aborígenes. Esta diversidad cultural es considerada una fuerte potencialidad pues enriquece la vida social y cultural local. En tercer lugar aparece como una fortaleza el posicionamiento estratégico que tiene la zona dentro del contexto regional, siendo un cruce de caminos de suma importancia a nivel regional, lo cual genera oportunidades en términos logísticos. La presencia de una población proactiva ha sido también considerada como una fortaleza local por parte de todos los entrevistados. Finalmente, para los actores locales la zona tiene un fuerte potencial turístico que podría ser motor de un mayor desarrollo económico y empleo.

FIGURA 3

Principales fortalezas de la localidad de El Colorado según la opinión de los actores locales

Disponibilidad y calidad de los recursos naturales

Diversidad cultural

Posicionamiento estratégico en la región

Población proactiva para construir dinámicas de desarrollo

Fuerte potencial turístico

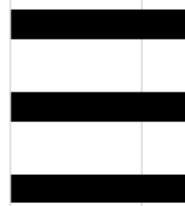

00

05

10

15

20

25

30

Fuente: Elaboración personal en base a entrevistas locales

Frente a las problemáticas y fortalezas planteadas a nivel local, interesa entender cuál es el futuro que los actores pretenden para su territorio, cuál es el deseo de futuro de la sociedad local y cómo es el territorio que los actores en mayor o menor medida han pensado, aunque esto no se explicite en términos de discursos y políticas. Es importante entender estos deseos de futuro pues la definición del proyecto de futuro (VANIER, 2015) es clave para la estructuración de la acción y de políticas, ya que la imagen de futuro puede favorecer la convergencia y concertación de múltiples actores en torno a un ideario del territorio (APPADURAI, 2015). Así los objetivos y escenarios deseados de futuro permiten construir utopías capaces de movilizar y concertar diferentes actores de la sociedad favoreciendo la constitución de un proyecto territorial a partir del cual la solidaridad y el juego de competencias se ordenan.

Así, la definición de un proyecto de futuro con sus objetivos actúa como marco de regulación de las energías y los conflictos sociales, en función de un proyecto colectivo. Este proyecto de futuro aparece entonces como el faro que orienta y hacia el cual se dirigen las acciones de una sociedad, actúa como utopía movilizadora de la sociedad pues lo que no es todavía actúa sobre la realidad actual. Así, el territorio se define y gestiona desde el presente a partir de un proyecto de futuro, poniendo en valor el legado histórico para adecuarlo a las exigencias actuales (FRANÇOIS; 
HIRCZAK; SENIL, 2006; LAJARGE, 2011). Desde el punto de vista analítico, y también desde una perspectiva de planificación, interesa entonces entender la tensión que se produce entre el presente y los objetivos y escenarios deseados para el futuro, ya sean implícitos o explícitos a través del discurso, pues esta tensión es la que promueve la acción territorial, materia prima de cualquier proceso de ordenamiento y desarrollo.

A partir de las entrevistas aparecen tres palabras claves vinculadas al futuro deseado: un mayor nivel educativo de la población (50\% de las entrevistas), mayor nivel de producción y empleo (30\%) y mayores servicios para la mejora de la calidad de vida (agua potable, vivienda, pavimento, electricidad, servicios sanitarios) con un $20 \%$ de las entrevistas. Así, el discurso sobre el escenario deseado puede resumirse como el de un territorio con una población con altos niveles educativos, con más producción agropecuaria, con los jóvenes trabajando en el campo, con procesamiento industrial de la producción y con más servicios en el pueblo.

Las ideas de crecimiento y modernización no operan como telón de fondo de las múltiples acciones locales, sino necesidades más básicas vinculadas a una educación que le permita a la sociedad tener capacidades para enfrentar su futuro, necesidades de empleo que garanticen el sustento y el arraigo en la localidad y finalmente una dotación de servicios y equipamientos que permitan una mejor calidad de vida. Este discurso o imaginario de futuro es claramente coherente con las problemáticas que los mismos actores locales observan en su territorio.

Dentro de este contexto, y sobre la base de este imaginario de futuro, emergen acciones territoriales de diverso tipo, el análisis de estas acciones debe permitir responder a tres preguntas claves: ¿qué acciones ponen en marcha los diferentes actores para construir el territorio de futuro deseado, teniendo en cuenta que no hay un claro escenario hacia donde avanzar?, ¿Cómo se ponen en marcha y se organizan dichas acciones?, y ¿qué resultados se generan?. Para poder responder a estas preguntas se realizo un relevamiento y análisis de las acciones, los actores involucrados en las mismas, la complejidad y la naturaleza de las acciones, y finalmente las opiniones y representaciones que los actores locales tienen sobre estas acciones y quienes las llevan adelante. La tabla siguiente da cuenta de estas acciones.

TABLA 2

Acciones y actores involucrados en la localidad de El Colorado

\begin{tabular}{|c|c|c|c|c|}
\hline \multirow{3}{*}{$\begin{array}{l}\text { Naturaleza de } \\
\text { las acciones }\end{array}$} & \multicolumn{4}{|c|}{ Tipos de actores involucrados } \\
\hline & \multicolumn{2}{|c|}{ Acción pública } & \multirow[b]{2}{*}{ Acción privada } & \multirow[b]{2}{*}{ Acción colectiva } \\
\hline & Local & $\begin{array}{c}\text { Provincial y } \\
\text { Nacional }\end{array}$ & & \\
\hline $\begin{array}{c}\text { Acciones } \\
\text { económicas y } \\
\text { productivas }\end{array}$ & & 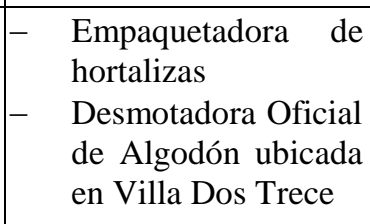 & $\begin{array}{l}\text { - Frigorífico } \\
\text { - Ganadería de } \\
\text { ciclo completo. }\end{array}$ & - Feria franca. \\
\hline $\begin{array}{c}\text { Acciones } \\
\text { Socioculturales }\end{array}$ & $\begin{array}{l}- \text { Fiestas } \\
\text { tradicionales } \\
\text { - Asistencia } \\
\text { social }\end{array}$ & & $\begin{array}{l}\text { - Bailes } \\
\text { Chamameceros } \\
\text { - Academias de } \\
\text { Baile }\end{array}$ & $\begin{array}{l}\text { - Feriarte } \\
\text { - Clubes de Futbol } \\
\text { - Basquet } \\
\text { - Academias de } \\
\quad \text { Baile }\end{array}$ \\
\hline $\begin{array}{c}\text { Acciones } \\
\text { político } \\
\text { institucionales }\end{array}$ & & & $\begin{array}{l}- \text { Remates } \\
\text { Ganaderos }\end{array}$ & $\begin{array}{l}\text { - Remates } \\
\text { Ganaderos }\end{array}$ \\
\hline
\end{tabular}




\begin{tabular}{|c|c|c|c|c|}
\hline $\begin{array}{c}\text { Acciones } \\
\text { ambientales }\end{array}$ & $\begin{array}{ll}\text { - Planta } & \text { de } \\
\text { Reciclado } & \\
\text { Urbano. } & \end{array}$ & & & \\
\hline $\begin{array}{l}\text { Acciones de } \\
\text { infraestructur } \\
\text { as }\end{array}$ & $\begin{array}{l}\text { - Pavimentación } \\
\text { de la planta } \\
\text { urbana. }\end{array}$ & $\begin{array}{l}\text { - Terminal de } \\
\text { ómnibus } \\
\text { - Matadero municipal } \\
\text { - Defensa contra } \\
\text { inundaciones }\end{array}$ & $\begin{array}{l}\text { - Taller de } \\
\text { tornería } \\
\text { Hidráulica. } \\
\text { - Ampliación de } \\
\text { Metalúrgica. }\end{array}$ & \\
\hline $\begin{array}{c}\text { Acciones de } \\
\text { ordenamiento } \\
\text { territorial }\end{array}$ & & $\begin{array}{l}\text { - Existe a Nivel } \\
\text { Provincial un POT. }\end{array}$ & & \\
\hline $\begin{array}{l}\text { Principales } \\
\text { recursos } \\
\text { movilizados }\end{array}$ & $\begin{array}{l}\text { - Nacionales de } \\
\text { coparticipación } \\
\text { - Fondo } \\
\text { Nacional de la } \\
\text { Soja } \\
\text { - Fondos de } \\
\text { recaudación } \\
\text { Municipal. }\end{array}$ & $\begin{array}{l}\text { - Nacionales de } \\
\text { coparticipación } \\
\text { - Fondo Nacional de } \\
\text { la Soja }\end{array}$ & $\begin{array}{lr}\text { Fondos } & \text { de } \\
\text { organizaciones } & y \\
\text { cámaras } & \\
\text { empresarias } & \end{array}$ & $\begin{array}{l}\text { Fondos de las } \\
\text { organizaciones }\end{array}$ \\
\hline
\end{tabular}

Fuente: Elaboración personal en base a entrevistas

La acción pública local (municipio) concentra sus acciones en la pavimentación de la planta urbana y en asistencia social (planes sociales, alimentarios, ayuda para emergencias médicas, etc.). La acción pública de nivel provincial y nacional por otro lado centra sus acciones en creación de infraestructuras y promoción del desarrollo productivo. La acción privada por otro lado esta centrada en la puesta en marcha de iniciativas productivas o empresariales, especialmente por parte de las familias más tradicionales. Finalmente la acción colectiva se centra en actividades culturales y religiosas.

La puesta en marcha de las acciones implica la existencia de un sistema de acción local desde donde se diseñan y ejecutan las mismas, es un sistema en donde interactúan múltiples actores, en donde cada uno de ellos se moviliza según sus intereses o sus redes de cooperación y solidaridad, pretendiendo influir, bloquear o activar estrategias de acción a partir de los distintos medios que se encuentran a su disposición. Este campo constituye entonces una arena (GIDDENS, 1984), un tejido de interacciones en el que concurren diferentes tomas de posición de los múltiples actores involucrados a través de la acción pública, la acción colectiva y la acción privada, con implicancias en el entramado decisional (SUBRA, 2008; FAURE, 2008; MASSON-VINCENT, 2008).

A mayor complejidad de las iniciativas y las acciones, mayor complejidad del modelo de organización y gobernanza seguido por los actores para llevar adelante las acciones que construyen territorio. En el caso de El Colorado este sistema o modelo de organización para la construcción de la acción territorial es básicamente combinado, ya que implica una complementariedad entre una lógica horizontal en la cual coexisten numerosas organizaciones con similares niveles jerárquicos (clubes, comisiones, asociaciones) que interactúan entre sí, y una lógica jerárquica de relación entre el Municipio y el Gobierno provincial que también plantea y ejecuta acciones a nivel local, la figura da cuenta del modelo de vinculación entre los actores dentro de la gobernanza local.

La figura $\mathrm{n}^{\circ} 4$ muestra el tipo de acción predominante (pública, privada y colectiva) y el tipo de proyectos que llevan adelante, además de los tipos de vínculos que construyen los actores para la construcción de sus acciones. Estos vínculos son mayormente débiles y oportunistas a nivel local, la mayor parte de las veces basadas en normas informales, claramente este tipo de vínculos se establece 
entre el sector público con el sector privado y con la acción colectiva, y entre la acción colectiva y la acción privada. Pero también pueden reconocerse vínculos fuertes e institucionalizados entre la acción pública provincial y local, dada las relaciones jerárquicas que se encuentran formalizadas jurídicamente e institucionalizadas en estructuras reglamentarias.

FIGURA 4

Organización de la acción territorial en la localidad de El Colorado

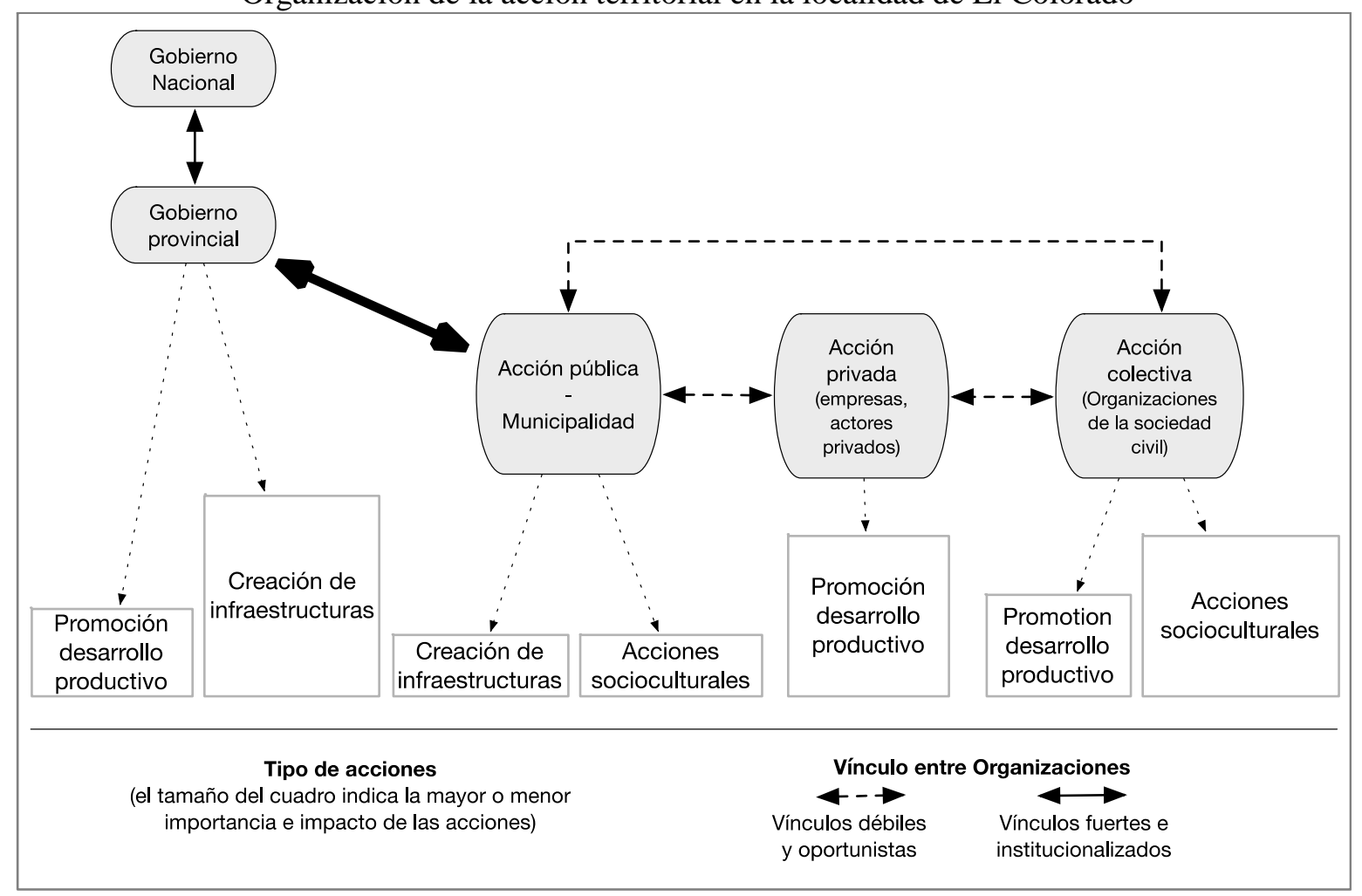

Fuente: elaboración personal

Teniendo en cuenta este modelo, interesa observar dos elementos directamente vinculado a la hipótesis de trabajo, la fuerte fragmentación de la acción territorial local y los liderazgos fragmentados, lo cual limita la capacidad de generar procesos sinérgicos de desarrollo.

Las relaciones horizontales dentro del sistema de organización local son muy fragmentadas, es decir, los vínculos entre la acción pública, la acción privada y la acción colectiva a nivel local son débiles y oportunistas, existe vinculación solo para casos muy específicos y de conveniencia para las organizaciones involucradas, pero una vez generada la acción o iniciativa que motivó la vinculación, este vínculo desaparece.

Esta lógica de organización fragmentaria de la acción territorial se vincula también a los marcos normativos que regulan el funcionamiento social. Así, en el caso específico del Departamento de Pirané las normas formales que reglamentan vínculos sólo se encuentran entre la acción pública de nivel provincial y de nivel local (municipalidad), pues existe un vínculo jerárquico y legal establecido por la constitución. (KNOEPFEL et al., 2007). Claramente, este vínculo esta supeditado también al juego político que establecen ambos niveles de gobierno, que en este caso es de convivencia y conveniencia mutua en tanto que ambos niveles políticos administrativos pertenecen al mismo partido político y construyen un mismo proyecto de poder, pero en niveles administrativos diferentes, lo importante aquí es que el nivel local necesita de los recursos del nivel provincial, y el nivel provincial necesita el caudal electoral que el nivel local puede recoger. Los otros vínculos locales se organizan bajo reglas o normas informales, dado el conocimiento y el sistema de valores, símbolos y normas de 
comportamiento compartidos por todos los actores (KNIGHT, 1992). Este sistema de normas, tanto formales como informales materializa las relaciones de poder entre los grupos sociales, facilitando o limitando las dinámicas de acción, en este sentido es importante reconocer, tal como lo plantea Freitas (2016) que la carencia de reglamentaciones reconocidas y estables a nivel local que regulen el funcionamiento de los múltiples actores en torno a un proyecto territorial, son también causa (y consecuencia) de la dispersión y fragmentación de acciones, y por lo tanto de la pérdida de sentido y eficacia de las mismas.

Desde el punto de vista del liderazgo local y la centralidad de un actor sobre el resto de los otros, si bien hay una clara intencionalidad política por parte del Municipio y del Gobierno provincial para estructurar el funcionamiento del territorio, la falta de intercambio de información y de construcción de proyectos compartidos pone en evidencia que no hay centralidad importante por parte de ningún actor local, es decir no hay liderazgos manifiestos capaces de estructurar el funcionamiento local, razón por la cual los múltiples actores intervienen en sus propias iniciativas sin vinculaciones constructoras de un futuro común.

Ahora bien, ¿Qué se logra a partir de las diferentes iniciativas puestas en marcha? Claramente un análisis pormenorizado permitiría cuantificar y describir la cantidad de eventos, los $\mathrm{km}$. de caminos pavimentados, las viviendas construidas, los planes y reglamentos de ordenamiento del uso del suelo, etc. Sin embargo, lo que interesa entender en materia de acción territorial no son esos datos en sí mismos, sino la percepción que los múltiples actores locales tienen sobre los resultados que el conjunto de las acciones han generado, pues es a partir de dichas percepciones y representaciones que los actores locales construyen nuevas dinámicas y acciones, bajo una lógica de ciclo permanente de acciones que se retroalimentan en función del éxito o logros ya obtenidos con anterioridad.

Todos los entrevistados manifiestan que no hay muchos logros en la comunidad, salvo la pavimentación de calles de los pueblos, algunas obras menores de infraestructura, la puesta en marcha de algún comercio nuevo y la creación de la feria de productores en el pueblo. Los actores locales no perciben cambios estructurales y la construcción de un proceso de desarrollo hacia el futuro, lo cual los sitúa en una posición de escepticismo frente al futuro y a las posibilidades de cambio para una mejora de vida, más allá de la pavimentación de las calles por parte de la Municipalidad.

\section{DISCUSIÓN}

Las acciones que se evidencian en El Colorado y en Pirané Sur no son el resultado de una visión compartida del futuro deseado por todos los actores locales, sino que terminan siendo acciones fragmentarias, de diversos individuos u organismos sin un proyecto común y compartido y sin resultados que satisfagan la idea de futuro planteada implícitamente por la comunidad, al contrario, a partir del diagnóstico y del relevamiento efectuado se observan procesos de deterioro territorial y ambiental (deterioro del paisaje urbano, crecimiento no controlado, deterioro ambiental, etc.), con baja capacidad de innovación y de generación de empleos, con un creciente deterioro social (aumento de problemas sociales, de inseguridad, etc.), y fundamentalmente con una creciente dependencia de actores no locales como son el gobierno provincial u algún inversor externo.

A partir de las entrevistas a múltiples actores pueden observarse que hay tres factores que, condicionados y reforzados mutuamente, limitan la construcción de dinámicas más virtuosas y consensuadas de desarrollo a nivel local.

El primero de estos factores es la carencia de un proyecto territorial de largo plazo, es decir una propuesta de futuro, consensuado y explicitado para el territorio. Esta falta de una visión y un proyecto compartido acelera y profundiza la fragmentación local y la incapacidad de valorizar las oportunidades que el territorio ofrece, empujando al mismo inexorablemente a un escenario tendencial que conjuga crecimiento urbano (debido ante todo a la migración de la población del campo al pueblo), pero creciente degradación social y ambiental. Esta orfandad de proyecto territorial 
se debe a varias razones, en primer lugar porque predomina una visión de corto plazo en el sistema de acción local, especialmente desde la acción pública, dada la lógica política electoral que privilegia la construcción de poder en el corto plazo y la resolución de problemas coyunturales en lugar de pensar el futuro territorial, en segundo lugar se debe a la carencia de capacidades técnicas y de gestión en el nivel local, especialmente en el sector público, responsable de liderar los procesos de planificación y gestión territorial. La carencia de cuadros técnicos necesarios para la planificación y la gestión del desarrollo es un hecho notorio, y cuando se requieren dichas capacidades, se contratan consultores que en muy poco tiempo diseñan una estrategia de desarrollo local con nulo o bajo nivel de participación y anclaje en las realidades locales.

El segundo factor es la profunda desarticulación y fragmentación de los actores locales, producto de una lógica política excluyente. Así cada uno de los actores involucrados en la vida local lleva adelante sus propias acciones y proyectos, pero ellos no se articulan entre sí, es más, en numerosos casos se genera una fuerte competencia entre estas acciones, prevaleciendo una lógica de exclusión por encima de lógicas de cooperación.

El tercer factor clave es la falta de liderazgos locales. La falta de actores con capacidad de liderar, construir consenso y dinamizar la vida local es un factor evidente, lo cual no permite por un lado construir esta visión y proyecto de largo plazo y en función de ello coordinar la multiplicidad de iniciativas locales.

\section{CONCLUSIONES}

La caracterización y el análisis del modelo de acción territorial de El Colorado y de Pirané Sur permiten rescatar cuatro grandes elementos o aprendizajes:

En primer lugar, el modelo de acción territorial que se ha construido en el área de trabajo responde a una idea de futuro o escenario centrado en un mayor nivel educativo, el aumento de la producción y la mejora de la calidad de vida. Dado que este escenario o ideal de futuro no es posible de construir dadas las condiciones estructurantes y "objetivas" del territorio (carencia de políticas educativas sólidas, bajo dinamismo económico comparado con las ciudades más grandes, carencia de infraestructuras, baja capacidad de gestión y ordenamiento), esta idea de futuro queda como frustración, como un ideal que no se puede alcanzar, frustración que se traduce en exclamaciones tales como: "en este pueblo no pasa nada", "para progresar hay que irse a la ciudad", pues en definitiva la ciudad es el "lugar" donde la modernidad y el progreso se materializa y se hace realidad (APPADURAI, 2015). Así, lo que se tiene es una contradicción, entre una imagen deseada del pueblo y campo que progresa y mejora, con empleo y mayores niveles educativos, y unas condiciones objetivas del territorio en la cual no hay mejora educativa, ni más empleo ni mejora de la calidad de vida. La consecuencia es que el futuro se presenta inexorable y lleno de conflictos y contradicciones, lo cual impele a los diferentes actores locales a centrar sus acciones en iniciativas de carácter paliativo o de defensa frente a una posible degradación de las condiciones de vida (trabajar para contener a los jóvenes, o para hacer sobrevivir a las Instituciones), pero no se generan iniciativas para construir un futuro deseado y consensuado por todos, más allá de la idea de la calidad de vida encarnada en más producción y más pavimento. Así, el futuro no se diseña, sino que se padece, pues es un futuro que evoca al crecimiento pero que advierte claramente y se resigna a la degradación. La experiencia local muestra entonces que para salir de esta trampa del trayectorismo occidental que conduce a un callejón sin salida de la modernidad + crecimiento, es necesario construir un sentido de futuro posible, de un proyecto territorial convocante y plural, tarea técnica pero ante todo política que implica la construcción compartida de una visión de futuro, para lo cual son necesarios los liderazgos locales.

En segundo lugar y desde otra perspectiva también se puede afirmar que los actores locales no tienen instrumentos ni métodos para construir un futuro deseado, pues los métodos empleados durante décadas en materia de planificación y gestión del desarrollo a nivel local ya no son eficaces. Las estrategias de actuación en solitario e individuales por las cuales cada uno lleva adelante sus acciones,

Papeles de Geografía, 65 (2019), 30-48 
con fuerte competencia entre actores por la presencia simbólica en el territorio (los partidos políticos, las asociaciones, los clubes, etc.), con estructuras burocráticas y administrativas jerárquicas (Municipio) y con acciones tradicionales, no permiten construir dinámicas innovadoras de desarrollo. Se requieren nuevas capacidades técnicas, y nuevas lógicas y métodos de gestión que respeten las diferentes rítmicas culturales, representaciones e imaginarios colectivos, y sean capaces de gestionar y animar redes multiactorales y multiescalares en busca de consensos.

En tercer lugar queda claro que las formas de organización y las redes de los actores dentro del territorio es un tema clave para dar cuenta como las sociedades construyen su desarrollo. Las condiciones de organización han cambiado en el último medio siglo, pues de la posición jerárquica que supo cumplir el Estado (en este caso el Municipio y la Provincia) en la animación y organización territorial, se pasó a un poder relacional centrado en redes de agentes que intervienen en ámbitos plurisectoriales y en múltiples niveles escalares (regionales, nacionales e internacionales). Estas redes accionan diversos tejidos y organizaciones colectivas y privadas que tienen un peso cada vez mayor en la organización de los territorios. No obstante, en el caso de El Colorado y Pirané Sur no se evidencia este cambio de lógica, el territorio parece estar sujeto a un férreo control municipal y provincial bajo una lógica de control político clientelar que no permite que la acción pública y la acción colectiva emerjan como co-constructora del desarrollo. En este sentido, si bien la acción privada y la acción pública concurren a la construcción del territorio, su rol se ve minimizado por la presencia monopólica de la acción pública local y provincial, no tanto en términos económicos, sino y ante todo simbólicos y organizacionales. (MONCAYO JIMÉNEZ, 2001; BOISIER, 2002; BERDEGUÉ, 2012).

Finalmente, se puede afirmar que el uso del concepto de acción territorial abre las puertas a pensar en las dinámicas de construcción del futuro de los territorios desde una perspectiva muy diferente, lejos de las premisas normativas sostenidas por el imaginario del desarrollo. Pensar la construcción del territorio desde una perspectiva de lo que los actores, en sus diferentes dimensiones escalares, realizan concretamente, permite entender los procesos tal como se dan en los territorios y por ende nos brinda mayor información para poder plantear proyectos de futuros más realistas, en función de las capacidades reales de los actores y no desde el imaginario del proyectista.

\section{REFERENCIAS BIBLIOGRÁFICAS}

APPADURAI, A. (2015): El futuro como hecho cultural. Ensayos sobre la condición global. Buenos Aires: Fondo de Cultura Económica.

BAUMAN, Z. (2017): Retrotopía. Buenos Aires: PAIDOS Estado y Sociedad.

BERDEGUÉ, J. (2012): Territorios en Movimiento: Dinámicas Territoriales Rurales en América Latina. Santiago: Centro Latinoamericano para el Desarrollo Rural, Documento de Trabajo, 110 pp.

BOISIER, S. (2002): La odisea del desarrollo territorial en américa latina. La búsqueda del desarrollo territorial y de la descentralización. En: SEMINARIO DESCENTRALIZACIÓN DE SECTORES SOCIALES: NUDOS CRÍTICOS Y ALTERNATIVAS. Lima. Ministerios de Educación y de Salud del Perú.

BOURDIEU, P. (2005): Capital cultural, escuela y espacio social. México: Siglo XXI.

BUSTOS CARA, R. (2008): Por una geografía de la acción territorial. En: JORNADAS CUYANAS DE GEOGRAFÍA. Mendoza: UNCUYO.

CEPAL (COMISIÓN ECONÓMICA PARA AMÉRICA LATINA) (2016): The social inequality matrix in Latin America. Santo Domingo.

CROZIER, M.; FRIEDBERG, E. (1997) : L'acteur et le systeme. Les contraites de l'action colective. París: Seuil.

DENTE, B.; SUBIRATS, J. (2014): Decisiones públicas: Análisis y estudio de los procesos de decisión en políticas públicas. Barcelona: Ariel.

Papeles de Geografía, 65 (2019), 30-48 
DOUILLET, A., NÉGRIER, E., \& FAURE, A. (2015) : Trois regards sur les politiques publiques vues du local, pp. 319-348.

FAURE, A. (2008): La question territoriale: pouvoirs locaux, action publique et politique(s). Grenoble: Cerat - Institut d'Etudes Politiques de Grenoble - Université Pierre Mendès France.

FRANÇOIS, H.; HIRCZAK, M.; SENIL, N. (2006) : Territoire et patrimoine: la coconstruction d'une dynamique et de ses ressources. Revue d'Economie Régionale et Urbaine, n. 5, pp. 683-700.

FREITAS, A. (2016): Por uma Abordagem Relacional do Desenvolvimento Territorial Rural. Rev. Econ. Sociol. Rural [online]. Vol.54, n.4, pp. 667-690. ISSN 0103-2003. http://dx.doi.org/10.1590/1234-56781806-94790540405.

GIDDENS, A. (1984) : La Constitución de la Sociedad. Buenos Aires, Amorrortu.

GRUENING, G. (2001): Origin and theoretical basis of new public management. International Public Management Journal, 4(1), pp. 1-25.

GUMUCHIAN, H., LAJARGE, R.; GRASSET, E.; ROUX, E. (2003) : Les acteurs, ces oubliés du territoire. Paris: Anthropos.

HARVEY, D. (203): Ciudades rebeldes. Del derecho de la ciudad a la revolución urbana. Buenos Aires: Akal Pensamiento crítico.

IPARRAGUIRRE, G. (2017): Imaginarios del desarrollo. Gestión política y científica de la cultura. Bueno Aires: Editorial Biblos CULTURALIA.

KEBIR, L. (2006) : Ressource et développement régional, quels enjeux? Revue d'Économie Régionale \& Urbaine, n. 5, pp. 701-723.

KNIGHT, H. (1992): Institutions and social conflict. Nueva York: Cambridge University Press.

KNOEPFEL, P.; LARRUE, C.; VARONE, F.; DIECK, M. (2007): Hacia un modelo de análisis de políticas públicas operativo. Un enfoque basado en los actores, sus recursos y las instituciones. Ciencia Política, n. 3, pp. 6-29.

LAJARGE, R. (2011) : Le développement territorial ou comment satisfaire le besoin grandissant de territorialités multiples. Fonder les Sciences Territoriales, pp. 128-132.

LANDEL, P.; PECQUEUR, B. (2011): L'operateur territorial, vecteur du changement. En: COLLOQUE ASSOCIATION DE SCIENCE RÉGIONALE DE LANGUE FRANÇAISE.

MANZANAL, M.; PONCE, M. (2012): La desigualdad ¿del desarrollo?. Controversias y disyuntivas del desarrollo rural en el Norte argentino. Buenos Aires: Ed. Ciccus.

MASSON-VINCENT, M. (2008): Governance and geography explaining the importance of regional planning to citizens, stakeholders in their living space. Boletín de la A.G.E., n. 46, pp. 363-367.

MOINE, A.; FAIVRE, E. (2013) : Le territoire comme un système complexe : de la représentation à l'action. 1'ere Conférence Intercontinentale d'Intelligence Territoriale 'Interdisciplinarité dans l'aménagement et développement des territoires", Oct 2011, Gatineau, Canada. pp.8, INTIInternational Network of Territorial Intelligence.

MONCAYO JIMÉNEZ, E. (20011): Evolución de los paradigmas y modelos interpretativos del desarrollo territorial. Santiago: Instituto Latinoamericano y del Caribe de Planificación Económica y Social. (Gestión Pública, 13)

POUTHIER, F. (2013) : Pourquoi et comment renouveler l'action territoriale aujourd'hui?. En: PIGNOT, L.; QUILES, J-P. (Coord.). Culture et Territoires: vers de nouvelles coopèrations des acteurs artistiques et culturels. Paris: Librairie des Territoires, Éditions de l'OPC. p. 28-33.

RIFFO, L. (2013) : 50 años del ILPES: evolución de los marcos conceptuales sobre desarrollo territorial. Santiago de Chile: CEPAL (Desarrollo Territorial, 15).

SILI, M. (2016): La acción territorial: una propuesta conceptual y metodológica para su análisis. Revista Brasilera de Estudios Urbanos regionales. San Pablo, V.20, N.1, p.11-31. Un modelo para comprender la dinámica de los territorios rurales. El caso de la Argentina. Mundo Agrario, v. 17, n. 34, e003, abril 2016.

SUBIRATS, J. (2015): Análisis de políticas públicas y gestión pública. Barcelona: Ariel.

SUBRA, P. (2008) : L'aménagement, une question géopolitique. Hérodote, v. 130, n. 3, p. 222-250.

Papeles de Geografía, 65 (2019), 30-48 
VANIER, M. (2015) : Demain les territoires. Capitalisme reticulaire et espace politique. Paris: Hermannn.

\section{Anexo: Guía de entrevistas para el análisis de la acción territorial}

1) Podría mencionar hasta 5 fortalezas o recursos potenciales de la zona de Pirané Sur (mencione en forma jerárquica)

2) Podría mencionar hasta 5 problemas o limitantes al desarrollo de la zona de Pirané Sur (mencione en forma jerárquica)

3) ¿Cuál es para Uds. el escenario deseado de futuro para la zona de Pirané Sur?

4) ¿Qué acciones, planes, programas y proyectos que generan cambios se están llevando a cabo en la zona?

5) ¿Con qué recursos se llevan adelante estas acciones?

6) ¿Qué actores están involucrados en estas acciones?

7) ¿Cómo se organizan los actores y que vinculaciones generan para llevar adelante estas acciones?

8) ¿Qué resultados concretos surgen de las acciones que se están llevando a cabo?

9) ¿Cuáles son los factores que inhiben o limitan las acciones locales en marcha? 